\title{
Satu Tinjauan Terhadap Tanggapan Guru-Guru dalam Penggunaan Platform Google Classroom bagi Proses Pembelajaran Sejarah
}

\author{
A Survey towards Teachers Perspective on the Use of Google Classroom Platform \\ for the Process of History Learning
}

\author{
M. Kaviza
}

SMK Padang Besar Utara, Perlis, Malaysia; kavizakaviza@yahoo.com

To cite this article (APA): Kaviza, M. (2020). Satu tinjauan terhadap tanggapan guru-guru dalam penggunaan platform Google Classroom bagi proses pembelajaran Sejarah. Journal of ICT in Education, 7(2), 74-80. https://doi.org/10.37134/jictie.vol7.2.7.2020

To link to this article: https://doi.org/10.37134/jictie.vol7.2.7.2020

\begin{abstract}
Abstrak
Kajian tinjauan ini bertujuan untuk menyelidik terhadap tanggapan seramai 60 orang guru dalam penggunaan platform Google Classroom bagi proses pembelajaran Sejarah. Kajian ini menggunakan instrumen soal selidik yang telah disahkan kesahannya serta memperolehi nilai kebolehpercayaan yang baik. Data yang diperolehi dari kajian ini dianalisis berdasarkan statistik deskriptif dan statistik inferensi melalui ujian-t sampel tak bersandar dengan menggunakan perisian IBM SPSS. Dapatan menunjukkan tahap tinjauan berdasarkan tanggapan guru-guru dalam penggunaan platform Google Classroom adalah tinggi. Dapatan kajian ini juga menunjukkan bahawa tahap tinjauan berdasarkan tanggapan guru lelaki dan guru perempuan dalam penggunaan platform Google Classroom berada pada tahap tinggi, walaupun dapatan kajian turut membuktikan bahawa tidak terdapat perbezaan yang signifikan bagi min tinjauan terhadap tanggapan guru-guru dalam penggunaan platform Google Classroom berdasarkan jantina. Implikasi kajian ini menjadi sumber rujukan kepada para guru Sejarah untuk menggunakan platform Google Classroom secara lebih interaktif dalam proses pembelajaran dan pemudahcaraan.
\end{abstract}

Kata Kunci: tanggapan, platform Google Classroom, pembelajaran sejarah, guru.

\begin{abstract}
This survey study aims to examine the perspective of a total of 60 teachers in the use of the Google Classroom platform for the process of History learning. This research a questionnaire as the research instrument which has been validated and has a good reliability value. The data of this study were statistically analyzed descriptively and inferentially through an independent sample t-test using IBM SPSS software. The findings indicated that the level of teachers' perspective in the use of the Google Classroom platform is high. The findings of this study have also shown that the level of male and female teachers' perspective in the use of the Google Classroom platform is high, even though the findings in the study also proved that there is no significant difference in the mean of teachers' perspective in the use of Google Classroom platform based on gender. The implications of this study
\end{abstract}


serve as a reference for History teachers to use the Google Classroom platform interactively in the process of learning and facilitation.

Keywords: perspective, Google Classroom platform, history learning, teacher.

\section{PENGENALAN}

Perubahan dalam sistem pendidikan yang telah menggalakkan penggunaan teknologi dan internet seperti platform Google Classroom yang dapat memudahkan pelaksanaan proses pengajaran dan pembelajaran secara Smart Classroom telah memberikan impak positif serta keberkesanannya terhadap hasil pembelajaran murid, di samping berpotensi untuk dijadikan platform atau medium dalam pelaksanaan proses pembelajaran abad ke-21 (PAK-21). Platform pembelajaran ini menjurus kepada strategi pembelajaran yang berpusatkan murid selaras dengan kurikulum yang dibentuk (Pusat Perkembangan Kurikulum (PPK), 2018; Kementerian Pendidikan Malaysia (KPM), 2013; Seuk, Seuk, Sedigheh \& Ainin, 2019). Platform Google Classroom merupakan perkhidmatan laman web secara percuma yang telah direkabentuk oleh pihak Google pada tahun 2014 kepada pihak sekolah atau ahli-ahli akademik serta guru-guru dalam membantu pelaksanaan proses pembelajaran secara maya (virtual) dari aspek mencipta, mengedar dan mengredkan tugasan murid dengan lebih mudah dan bermakna (Swita \& Heri, 2019; Sukmawati, 2020). Tambahan pula, penggunaan platform Google Classroom juga dapat memudahkan guru-guru untuk menyampaikan maklumat dan pengetahuan dengan lebih sistematik, di samping murid-murid juga berasa lebih selesa dan aktif dalam proses pembinaan pengetahuan dan kemahiran mereka (Fauzan \& Fatkhul, 2019; Hakim, 2016).

Sungguhpun begitu, tanggapan guru-guru terhadap penggunaan platform Google Classroom bagi proses pembelajaran dan pemudahcaraan masih belum diketahui lagi. Hal ini rentetan daripada kajian-kajian lepas yang melaporkan bahawa murid-murid telah pun berminat, berpuas hati dan bersedia untuk menggunakan platform Google Classroom dalam proses pembelajaran dan pemudahcaraan mereka (Nor Zanira Abd Manan \& Hafizul Fahri Hanafi, 2019; Izwan Nizal Mohd Shaharanee, Jastini Mohd Jamil \& Sarah Syamimi Mohammad Rodzi, 2016; Kaviza, 2020). Justeru, wujud keperluan untuk mengenal pasti tanggapan guru-guru dalam penggunaan platform Google Classroom sebagai suatu tinjauan awal dalam merancang, merekabentuk dan melaksanakan proses pembelajaran dan pemudahcaraan melalui penggunaan platform Google Classroom, khususnya dalam proses pembelajaran Sejarah. Maka, tujuan kajian ini ialah untuk mengenal pasti tahap tinjauan terhadap tanggapan guru-guru dalam penggunaan platform Google Classroom bagi proses pembelajaran Sejarah.

\section{OBJEKTIF KAJIAN}

Terdapat tiga objektif kajian yang dibincangkan iaitu: 
1) Mengenal pasti tahap tinjauan terhadap tanggapan guru-guru dalam penggunaan platform Google Classroom bagi proses pembelajaran Sejarah.

2) Mengenal pasti tahap tinjauan terhadap tanggapan guru lelaki dan perempuan dalam penggunaan platform Google Classroom bagi proses pembelajaran Sejarah

3) Mengenal pasti perbezaan min bagi tinjauan terhadap tanggapan guru-guru dalam penggunaan platform Google Classroom bagi proses pembelajaran Sejarah berdasarkan jantina.

\section{PERSOALAN KAJIAN}

Terdapat tiga persoalan kajian yang terlibat dalam kajian ini iaitu:

1) Apakah tahap tinjauan terhadap tanggapan guru-guru dalam penggunaan platform Google Classroom bagi proses pembelajaran Sejarah?

2) Apakah tahap tinjauan terhadap tanggapan guru lelaki dan perempuan dalam penggunaan platform Google Classroom bagi proses pembelajaran Sejarah?

3) Adakah terdapat perbezaan min bagi tinjauan terhadap tanggapan guru-guru dalam penggunaan platform Google Classroom bagi proses pembelajaran Sejarah berdasarkan jantina?

\section{HIPOTESIS KAJIAN}

Hipotesis kajian berikut telah dibentuk bagi menjawab persoalan kajian yang ketiga dengan pengujian pada aras kesignifikan $(\mathrm{p}=0.05)$ iaitu:

Ho1: Tidak terdapat perbezaan min yang signifikan bagi tinjauan terhadap tanggapan guru-guru dalam penggunaan platform Google Classroom bagi proses pembelajaran Sejarah berdasarkan jantina.

\section{METODOLOGI KAJIAN}

Kajian ini telah menggunakan reka bentuk kajian tinjauan disebabkan oleh reka bentuk kajian tinjauan ini adalah bersesuaian dengan tujuan kajian ini iaitu untuk meninjau tanggapan terhadap pandangan, atau persepsi guru-guru. Seramai 60 orang guru yang telah ditentukan berdasarkan teknik persampelan rawak terlibat dalam kajian sebagai sampel kajian.

Instrumen kajian ini merupakan satu soal selidik yang menggunakan skala Likert lima mata yang telah disahkan dan mempunyai nilai ketekalan Cronbach Alpha iaitu 0.95. Nilai ini boleh dianggap baik dan diterima bagi tujuan kajian ini (Nunnally \& Bernstein, 1994). Data kajian telah dianalisis secara statistik deskriptif dan statistik inferensi. Statistik inferensi dilaksanakan mennggunakan ujian-t bagi sampel tak bersandar melalui perisian IBM SPSS versi 21. Kajian ini menggunakan interpretasi tahap min yang diadaptasi daripada Jamil Ahmad (2002) seperti yang ditunjukkan pada Jadual 1. 
Jadual 1: Interpretasi Min dan Tahap

\begin{tabular}{cc}
\hline Skor Min & Tahap \\
\hline $3.67-5.00$ & Tinggi \\
$2.34-3.66$ & Sederhana \\
$1.00-2.33$ & Rendah \\
\hline
\end{tabular}

\section{DAPATAN KAJIAN}

Dapatan kajian dilaporkan berdasarkan tiga persoalan kajian yang telah disenaraikan sebelum ini.

\section{Persoalan Kajian 1}

Apakah tahap tinjauan terhadap tanggapan guru-guru dalam penggunaan platform Google Classroom bagi proses pembelajaran Sejarah?

Berdasarkan Jadual 2, tahap tinjauan terhadap tanggapan guru-guru dalam penggunaan Google Classroom bagi proses pembelajaran Sejarah adalah tinggi $(\mathrm{M}=3.81, \mathrm{SD}=0.39)$. Justeru, dapat dirumuskan bahawa tahap tinjauan terhadap tanggapan guru-guru dalam penggunaan Google Classroom bagi proses pembelajaran Sejarah berada pada tahap tinggi dalam kajian ini.

Jadual 2: Min dan Sisihan Piawai bagi Tinjauan Terhadap Tanggapan Guru-Guru dalam Penggunaan Google Classroom bagi Proses Pembelajaran Sejarah

\begin{tabular}{llcl}
\hline & Min & Sisihan Piawai & Tahap \\
\hline Tanggapan guru & 3.81 & 0.39 & Tinggi \\
\hline
\end{tabular}

\section{Persoalan Kajian 2}

Apakah tahap tinjauan terhadap tanggapan guru lelaki dan perempuan dalam penggunaan platform Google Classroom bagi proses pembelajaran Sejarah?

Berdasarkan Jadual 3, tahap tinjauan terhadap tanggapan guru lelaki $(\mathrm{M}=3.70, \mathrm{SD}=0.34)$ dan guru perempuan $(\mathrm{M}=3.86, \mathrm{SD}=0.40)$ dalam penggunaan platform Google Classroom bagi proses pembelajaran Sejarah adalah tinggi Namun begitu, tahap tinjauan terhadap tanggapan guru perempuan dalam penggunaan Google Classroom sebagai proses pembelajaran Sejarah adalah didapati lebih tinggi berbanding dengan guru lelaki dalam kajian ini. Justeru, dapat dirumuskan bahawa tahap tinjauan terhadap tanggapan guru lelaki dan guru perempuan dalam penggunaan platform Google Classroom bagi proses pembelajaran Sejarah adalah tinggi dalam kajian ini.

Jadual 3: Min dan Sisihan Piawai bagi Tinjauan Terhadap Tanggapan Guru-Guru dalam Penggunaan Google Classroom bagi Proses Pembelajaran Sejarah Berdasarkan Jantina

\begin{tabular}{ccccccc}
\hline & \multicolumn{3}{c}{ Guru Lelaki (N=21) } & \multicolumn{3}{c}{ Guru Perempuan (N=39) } \\
\hline & Min (M) & $\begin{array}{c}\text { Sisihan } \\
\text { Piawai (SD) }\end{array}$ & Tahap & Min (M) & $\begin{array}{c}\text { Sisihan Piawai } \\
\text { (SD) }\end{array}$ & Tahap \\
\cline { 2 - 7 } Tanggapan guru & 3.70 & 0.34 & Tinggi & 3.86 & 0.40 & Tinggi \\
\hline
\end{tabular}




\section{Persoalan Kajian 3}

Adakah terdapat perbezaan min bagi tinjauan terhadap tanggapan guru-guru dalam penggunaan platform Google Classroom bagi proses pembelajaran Sejarah berdasarkan jantina?

Berasaskan keputusan ujian Levene's yang tidak signifikan $(\mathrm{F}=0.02, \mathrm{p}=0.89)$ dalam Jadual 4, keputusan ujian-t sampel tak bersandar telah melaporkan bahawa tidak terdapat perbezaan yang signifikan min tinjauan terhadap tanggapan guru-guru dalam penggunaan platform Google Classroom bagi proses pembelajaran Sejarah $[\mathrm{t}(58)=-1.60, \mathrm{p}=0.11]$ berdasarkan jantina. Secara rumusannya, Ho1 gagal ditolak. Maka, dapat disimpulkan bahawa tidak terdapat perbezaan min tinjauan terhadap tanggapan guru-guru dalam penggunaan platform Google Classroom bagi proses pembelajaran Sejarah antara guru lelaki dengan guru perempuan dalam kajian ini.

Jadual 4: Ujian-t Sampel Tak Bersandar bagi Perbezaan Min Bagi Tinjauan Tanggapan Terhadap Penggunaan Platform Google Classroom bagi Proses Pembelajaran Sejarah Berdasarkan Jantina

\begin{tabular}{|c|c|c|c|c|c|c|c|c|c|}
\hline & \multicolumn{7}{|c|}{ Ujian-t bagi persamaan min } & & \\
\hline & \multicolumn{2}{|c|}{ Ujian Levene's } & \multirow[t]{2}{*}{$\mathbf{t}$} & \multirow[t]{2}{*}{ df } & \multirow[t]{2}{*}{$\mathbf{p}$} & \multirow[t]{2}{*}{ Perbezaan min } & \multirow{2}{*}{$\begin{array}{c}\text { Min } \\
\text { ralat } \\
\text { Piawai }\end{array}$} & \multicolumn{2}{|c|}{$\begin{array}{l}\text { 99\% selang keyakinan bagi } \\
\text { perbezaan }\end{array}$} \\
\hline & $\mathbf{F}$ & Sig. & & & & & & Bawah & Atas \\
\hline Perbezaan Min & 0.02 & 0.89 & -1.60 & 58 & 0.11 & -0.17 & 0.10 & -0.38 & 0.04 \\
\hline
\end{tabular}

\section{PERBINCANGAN KAJIAN}

Hasil kajian ini telah menunjukkan bahawa tahap tinjauan terhadap tanggapan guru-guru dalam penggunaan platform Google Classroom bagi proses pembelajaran Sejarah yang tinggi. Dapatan ini adalah konsisten dengan dapatan kajian Siti Salwa Atan dan Jamaludin Badusah (2013) yang telah melaporkan bahawa tahap sikap guru-guru dalam menggunakan aplikasi rangkaian sosial Google Plus dalam proses pengajaran dan pembelajaran komponen sastera adalah sangat positif dan kajian Muhammad, Wibowo dan Jan (2019) yang juga telah melaporkan bahawa guru-guru pelatih memberi sudut pandangan bahawa penggunaan Learning Management System (LMS) melalui platform Google Classroom dapat memudahkan pelaksanaan proses pembelajaran dan dapat meningkatkan kualiti pembelajaran. Tambahan pula, dapatan kajian Almio dan Sri (2019) dan kajian Kaukah (2018) yang telah dijalankan berdasarkan pendekatan kualitatif telah melaporkan bahawa guru-guru adalah berpersepsi baik dalam menggunakan platform Google Classroom sebagai alat pemudahcaraan yang dapat menggalakkan murid-murid untuk menyiapkan tugasan dan menguruskan dokumen, dapat menjana interaksi dua hala antara murid dan guru serta dapat mengorganisasikan pengurusan kelas dengan lebih baik yang secara tidak langsung telah dapat menyokong dapatan kajian ini. Hal ini demikian kerana guru-guru telah mengakui manfaat dan potensi pengingtegrasian platform Google Classroom dalam proses pembelajaran dan pemudahcaraan serta sebagai platform pembelajaran dalam strategi pembelajaran secara teradun (blended learning) yang memberi impak positif dalam mengoptimumkan hasil pembelajaran dalam kalangan murid (Ul, Lilis \& Trisnendri, 2019; Ahmad \& Ahmad, 2020; Eko \& Rahmatullah, 2020). 
Di samping itu, tahap tinjauan terhadap tanggapan guru-guru dalam penggunaan platform Google Classroom bagi proses pembelajaran Sejarah yang tinggi bagi guru lelaki dan guru perempuan adalah sealiran dengan dapatan kajian Lejla, Arbana, mariku, Edmond dan Hyrije (2018) yang telah mendapati bahawa penggunaan Learning Management System adalah lebih baik bagi murid perempuan berbanding dengan murid lelaki. Tambahan pula, dapatan kajian ini yang menunjukkan bahawa tidak terdapat perbezaan yang signifikan bagi min tinjauan terhadap tanggapan guru-guru dalam penggunaan platform Google Classroom bagi proses pembelajaran Sejarah berdasarkan jantina adalah sealiran dengan dapatan kajian Rana Hamzah dan Zamri Mahamod (2017) yang telah melaporkan bahawa tidak terdapat perbezaan yang signifikan bagi min penggunaan aplikasi Google Plus dalam pembelajaran dan pemudahcaraan (PdPc) Bahasa Melayu dan kajian Wichadee (2015) yang telah mendapati bahawa tidak terdapat perbezaan yang signifikan bagi min sikap terhadap penggunaan Learning Management System dalam kalangan tenaga pengajar. Justeru, dapat dirumuskan bahawa tahap tinjauan terhadap tanggapan guru-guru dalam penggunaan platform Google Classroom bagi proses pembelajaran Sejarah adalah tinggi dalam kajian ini.

\section{KESIMPULAN}

Kesimpulannya, tahap tinjauan terhadap tanggapan guru-guru dalam penggunaan platform Google Classroom bagi proses pembelajaran Sejarah adalah tinggi dalam kajian ini. Implikasinya, kajian ini telah mencadangkan kepada guru-guru untuk menggunakan platform Google Classroom dalam proses pembelajaran Sejarah secara lebih meluas lagi bagi menghadapi proses transformasi pembelajaran yang berasaskan internet dan komputer.

\section{RUJUKAN}

Ahmad, A.Y \& Ahmad, S. (2020). Google Classroom as learning platform in teaching writing. Jurnal Bahasa dan Sastera Inggeris, 9(1), 48-64.

Almio, S.H. \& Sri, S. (2019). Teacher's experiences on the use of Google Classroom. In proceedings of the 3rd English Language and Literature International Conferences, 172-178.

Eko, P.S \& Rahmatullah. (2020). Optimalisasi pembelajaran pendidikan agama Islam (PAI) melalui Google Classroom. Jurnal Piwulang, 2(2), 129-143.

Fauzan \& Fatkhul Arifin (2019). The effectiveness of Google Classroom Media on the Students' Learning Outcomes of Madrasah Ibtidaiyah Teacher Education Department. AL IBTIDA: Jurnal Pendidikan Guru Mi, 6(2), 271-285.

Hakim, A.B. (2016). Efektifitas Penggunaan E-Learning Moodle, Google Classroom and Edmodo. I-STATEMENT, 2(1), 1-6.

Izwan Nizal Mohd Shaharanee, Jastini Mohd Jamil \& Sarah Syamimi Mohammad Rodzi. (2016). The application of Google Classroom as a tool for teaching and learning. Journal of Telecommunication Electronic and Computer Engineering, $8(10), 5-8$.

Jamil Ahmad (2002). Pemupukan budaya penyelidikan di kalangan guru di sekolah: Satu penilaian. Tesis Ijazah Kedoktoran, Fakulti Pendidikan, Universiti Kebangsaan Malaysia.

Kaukah, A.Z. (2018). Effectiveness of Google Classroom: teacher's perceptions. PRIZEEN: Social Science Journal, 2(2), 5266.

Kaviza, M. (2020). Kesediaan murid terhadap penggunaan aplikasi Google Classroom sebagai platform pembelajaran sejarah. Malaysian Journal Social Sciences and Humanities, 5(4), 108-115.

Kementerian Pendidikan Malaysia. (2013). Pelan Pembangunan Pendidikan Malaysia 2013-2025. Putrajaya: Kementerian Pendidikan Malaysia.

Lejla, A.B., Arbana, K., Mariku, A.T., Edmond, J., \& Hyrije, A.A. (2018). LMS Solution: Evidence of Google Classroom usage in Higher Education. Business Systems Research, 9(1), 31-43.

Muhammad, L.H., Wibowo, H.P \& Jan, W. (2019). Pre-service student teachers perception of using Google Classroom in a 
Blended course. Humanities \& Social Sciences Reviews, 7(2), 363-368.

Nor Zanira Abd Manan \& Hafizul Fahri Hanafi (2019). Google Classroom: Student's acceptance using UTAUT Model. JAPPA: Journal of Applied Art, 1(1), 64-72.

Nunnally, J.C., \& Bernstein, I.H. (1994). Psychometric theory (3rd ed.). New York: McGraw Hill.

Pusat Perkembangan Kurikulum. (2018). Dokumen Standard Kurikulum dan Pentaksiran Sejarah Tingkatan 4 dan 5. Putrajaya: Kementerian Pendidikan Malaysia.

Rana Hamzah \& Zamri Mahamod (2017). Aplikasi Google Plus dalam pembelajaran dan pemudahcaraan (PdPc) Bahasa Melayu murid sekolah rendah. In proceedings of Seminar Serantau, 652-660.

Seuk, Y.P., Seuk, W.P., Sedigheb, M., \& Ainin, S. (2019). Effect of Smart Classroom on student achievement at Higher Education. Journal of Educational Technology Systems, 1-14.

Siti Salwa Atan \& Jamaludin Badusah. (2013). Aplikasi rangkaian sosial Google Plus dalam Pengajaran dan Pembelajaran Komponen Sastera. Jurnal Pendidikan Bahasa Melayu, 3(1), 31-41.

Sukmawati. (2020). Implementasi pemanfaatan Google Classroom dalam proses pembelajaran online di Era Industri 4.0. Jurnal Kreatif Online, 8(1), 39-46.

Swita, A.H. \& Heri, P. (2019). Pemanfaatan Google Classroom sebagai media pembelajaran online di universitas dian Nuswantoro. WACANA, 18(2), 225-233.

Ul, N.E., Lilis, S \& Trisnendri, S. (2019). Penerapan Google Classroom dalam Pembelajaran Bahasa Inggeris kepada guruguru Bahasa Inggeris SMP di Subang. Jurnal Pengabdian kepada Masyarakat, 2(2), 183-191.

Wichadee, S. (2015). Factors related to faculty members' attitude and adoption of a learning management system. Turkish Online Journal of Educational Technology, 14(4), 53-61. 